Illinois State University

ISU ReD: Research and eData

Theses and Dissertations

$1-26-2015$

\title{
Live Like You Were Dying: How Transitions Affect Decisions of Undergraduate University Students
}

Danielle N. Freund

Illinois State University, daniellefreund1@gmail.com

Follow this and additional works at: https://ir.library.illinoisstate.edu/etd

Part of the Psychology Commons

\section{Recommended Citation}

Freund, Danielle N., "Live Like You Were Dying: How Transitions Affect Decisions of Undergraduate University Students" (2015). Theses and Dissertations. 303.

https://ir.library.illinoisstate.edu/etd/303

This Thesis is brought to you for free and open access by ISU ReD: Research and eData. It has been accepted for inclusion in Theses and Dissertations by an authorized administrator of ISU ReD: Research and eData. For more information, please contact ISUReD@ilstu.edu. 


\title{
LIVE LIKE YOU WERE DYING: HOW TRANSITIONS AFFECT DECISIONS OF UNDERGRADUATE UNIVERSITY STUDENTS
}

\author{
Danielle N. Freund
}

58 Pages

May 2015

The current study explored differences in university students' affect, timeselectivity, and deliberation based on year at the university and random assignment to a graduation salience or non-graduation salience condition. Senior participants reported a significant difference between the proportion of time they intended to spend in academic and social activities. There was a main effect for time on positive and negative affect, but no other main effects or interactions were found. Implications for SST and TMT are discussed as are directions for future research. 
LIVE LIKE YOU WERE DYING: HOW TRANSITIONS AFFECT

DECISIONS OF UNDERGRADUATE

UNIVERSITY STUDENTS

DANIELLE N. FREUND

A Thesis Submitted in Partial

Fulfillment of the Requirements for the Degree of

MASTER OF SCIENCE

Department of Psychology

ILLINOIS STATE UNIVERSITY

2015 
(C) 2015 Danielle N. Freund 
LIVE LIKE YOU WERE DYING: HOW TRANSITIONS AFFECT

DEICISIONS OF UNDERGRADUATE

UNIVERSITY STUDENTS

DANIELLE N. FREUND

COMMITTEE MEMBERS:

Michael J. Stevens, Chair

W. Joel Schneider 


\section{ACKNOWLEDGMENTS}

The writer wishes to thank the following people for their continuous support throughout the completion of this project. First, the writer wishes to thank her chair, Dr. Michael Stevens for his patience, encouragement, willingness to try new methods, and for always being so generous with his time and dedication to this project. The writer wishes to thank Dr. W. Joel Schneider for his kindness when challenging and coaching this writer. The writer wishes to thank Dr. Karla Doepke for her thoughtful feedback on this project and for her mentorship in both undergrad and graduate school. This writer wishes to thank all of her graduate professors for their inspiration and wisdom that facilitated this project and helped her through each step of the program. Finally, this writer wishes to thank her family and friends for their unrelenting reassurance, open ears, and comic relief throughout the completion of the program. Thank you all so very, very much.

D.N.F. 


\section{CONTENTS}

\section{Page}

ACKNOWLEDGMENTS $\quad$ i

CONTENTS

TABLES $\quad$ iv

CHAPTER

I. PROBLEM STATEMENT 1

Research Problem and Purpose 4

II. REVIEW OF THE LITERATURE 6

Socioemotional Selectivity Theory $\quad 6$

$\begin{array}{lr}\text { Terror Management Theory } & 16\end{array}$

Ties that Bind SST and TMT 20

Research Questions $\quad 22$

Hypotheses $\quad 23$

Activity - Time Selectivity Matrix $\quad 23$

Deliberation $\quad 24$

I-PANAS-SF $\quad 25$

III. METHOD 26

Participants $\quad 26$

$\begin{array}{ll}\text { Materials } & 26\end{array}$

Activity - Time Selectivity Matrix $\quad 26$

Deliberation Item $\quad 27$

I-PANAS-SF $\quad 28$

Demographic Form $\quad 29$

$\begin{array}{ll}\text { Procedure } & 29\end{array}$

Design 31 
IV. RESULTS 32

V. DISCUSSION 40

Limitations $\quad 43$

Implications and Future Directions $\quad 44$

REFERENCES $\quad 48$

APPENDIX A: Activity - Time Selectivity Matrix 51

APPENDIX B: I-PANAS-SF 53

APPENDIX C: Demographic Questionnaire 55

APPENDIX D: Informed Consent 57 


\section{TABLES}

Table

Page

1. Means and Standard Deviations of Seniors' Reported

Proportion of Time Selectivity by Activity

2. Means and Standard Deviations of Proportion of Time Spent in Activities by Year in University and Salience Condition

3. Deliberation Scores by Year in University and Salience Condition 


\section{CHAPTER I}

\section{PROBLEM STATEMENT}

There are two main theories on which this research is based. The first is Socioemotional Selectivity Theory (SST; Carstensen, 1995). SST postulates that the motivations of young adults are future-focused and information seeking. Per SST, young adults are concerned about meeting new people and career advancement in the long run. As individuals become older, approaching the social ending of death, their motivations become more present-focused. Per SST, older adults are concerned about regulating their emotions (being happier in the here-and-now) and spending time with family and familiar friends. The popular song "Live Like You Were Dying" (mcgraw, 2004, track 5) encourages listeners to embrace the opportunities they have in life by focusing on their approaching death. The recognition that death is impending prompts older individuals to act in ways that are more present-focused. While death due to old age is a common social ending that prompts these changes in motivations, this is not the only social ending. Real and perceived social endings such as an HIV diagnosis with symptoms of AIDS, political transitions, and graduation from college can elicit these changes in motivations for individuals as well.

The other theory this research is based on is Terror Management Theory (TMT; Greenberg, Solomon, Veeder, Pyszczynski, Rosenblatt, \& Kirkland, 1990). TMT's foundation is in existential psychology, which posits that psychopathology 
stems from conflicts that reflect with the nature of human existence. In particular, existential psychology identifies four concerns that individuals are confronted with: death, freedom, isolation, and meaninglessness (Yalom, 1980). TMT reflects this existential concern of death and posits that when we become aware of our own mortality (mortality salience), we tend to cling to our standards and values. Standards and values are an internal compass that individuals use to navigate their choices throughout life. When these standards and values are challenged or threatened, people may fear the loss of meaning and purpose, as they experience their constructed "reality" as acutely fragile.

TMT is a vast theory, so the main aspects of TMT that will be discussed in this thesis reflect the connection between TMT and interpersonal relationships. As naturally social beings, the majority of people value their relationships with family, friends, and other social acquaintances. The people that we choose to spend time with provide emotional and tangible support when we are in times of need. Given the important role of our social partners, it is reasonable that we would cling to our relationships when we are confronted with the issue of death. People value their relationships because they provide a source of support and a reminder of the meaningful lives we have created. TMT research has found that when individuals are reminded of their mortality, they are more likely to change their standards to find a partner (Hirschberger, Florian, \& Mikulincer, 2002), they report increased commitment in their relationships (Hirschberger, et al.,2002), and they are more likely to exaggerate the positive regard they may receive from romantic partners (Cox \& Arndt, 2012). 
The following research will study college as a social ending. College is a time when students are presented with an array of novel opportunities that they may never be faced with again. They typically move out of their childhood homes into a more independent living experience where they are expected to complete their higher education and learn what it means to be an adult. For most college students, this time is ideal for finding themselves, learning from mistakes, and meeting people who will impact their lives. Whether students drop out, transfer, or graduate, college will eventually end, and so will the opportunity for these unique experiences.

School systems face the same problem year after year: "senioritis". Many high school and college seniors claim to have "senioritis", which is commonly understood to mean the lack of motivation towards academic achievement due to impending graduation. Many teachers see seniors as lazy students with little if any drive and ambition, although many teachers and guidance counselors identify the highest achieving students to be most at risk for senioritis (Hoover, 2003). SST and TMT may explain senioritis in a more psychologically meaningful light. Seniors may not become disengaged academically because they do not care; rather, SST and TMT posit that seniors' motivation may have shifted from an academic focus to a social focus in order to regulate emotions related to their impending graduation and end of important relationships. If teachers want to help these students stay focused on school, they need to understand the reason for this particular motivational change. Programs are being developed that will help students stay academically motivated with incentives related to career building (Dunn, 2001), but if the problem lies in the social consequences of 
impending graduation, then these programs may be of little help. The previously reviewed research has focused on transitions over the lifespan. A few articles (Fredrickson, 1995; Pruzan \& Isaacowitz, 2006) have focused specifically on transitions from college life to early adulthood, but to this author's knowledge no research has been conducted to understand how young adults experience and make decisions in response to this transition point. Are these seniors really slacking off? They may be slacking off academically, but SST and TMT would posit that they are redirecting their attention to relationships that have become especially important given an impending, social transition. This would parallel the concerns found in existential psychology, particularly in regards to meaningfulness, one of the existential issues previously noted. If seniors are focusing their attention on relationships pending graduation from college or high school, research further suggests that they may also focus on the quality of their close relationships. When searching for meaning in transitional times, seniors may find comfort and fulfillment in the enhancement of their significant friendships rather than through the completion of academic work. If students' responses to the inevitable end of college life, such as affect and decisions on how to spend their time, can be predicted, universities and teachers may be able to adjust their expectations and curricula for better success and overall well being of their students.

\section{Research Problem and Purpose}

How does closeness in time of graduation impact university students in regards to their affect, decisions, and thoughtfulness of their decisions? 
To address the issue of how graduation affects students, this study examined the links between the salience of graduation and positive affect, negative affect, decisions about how to allocate time, and deliberation put into these decisions. This study gathered data using an online survey with a sample of university sophomores and graduating seniors at a large, Midwestern university. The survey consisted of demographic items, measures of positive and negative affect, an activity in which students chose how to allocate their time, and a measure of the thoughtfulness of their time-allocation decisions. 


\section{CHAPTER II}

\section{REVIEW OF THE LITERATURE \\ Socioemotional Selectivity Theory}

Fredrickson and Carstensen (1990) compared differences in social selectivity across the lifespan. Using random dialing, researchers called potential participants and asked if they would be willing to answer questions about how they spend their free time. They were read the following unlimited time scenario:

Imagine that you have half an hour of free time, with no pressing commitments. You have decided that you would like to spend this time with another person. Assuming that the following three people were available to you, with which person would you choose to spend that time?

After listening to this time-unconstrained scenario, participants were asked with whom they would like to spend a half hour of free time. The possible partners were intended to represent emotional (social partners who would elicit an emotional connection), informational (social partners who would provide information), and future-relevant (social partners with whom the participant may have a deeper relationship in the future) social partners. The options that participants could choose from were: "A member of your immediate family" (emotional), "The author of a book you have just read" (informational), and “A recent acquaintance with whom you seem to have much in common" (futurerelevant). After choosing the time-unconstrained scenario, participants were read the following time-limited scenario: 
Now imagine this new situation: In just a few weeks, you plan to move across the country - by yourself. No member of your family and your current social circle will be accompanying you on this cross-country move. Although you are preparing for your big departure, you find that you have half an hour of free time, with no pressing commitment. You have decided that you'd like to spend this time with another person. Assuming that the following three people are available to you, which person would you choose to spend that time with?

Participants then chose from the same potential social partners as in the first scenario. The results showed that when there were no constraints on time, older adults were significantly more likely to choose a familiar social partner as compared to younger adults. However, when time constraints were introduced in the second scenario, there was no significant difference between younger and older adults in the choice of a familiar social partner. There was a significant within-subjects increase in choice of a familiar social partner among young adults from the time-unconstrained to the time-constrained scenario.

Dudley and Multhaup (2005) replicated this study, but changed the novel social partner options in the constrained-time scenario to include "a person who lives where you are moving to who happens to be in town visiting" instead of "the author of a book you have just read.” Despite the personally relevant information that this novel social partner could offer, younger and older adults chose a familiar social partner significantly more often. Both studies provide support for SST by showing that older adults are more likely to choose familiar social partners in constrained and unconstrained-time conditions. Furthermore, younger adults are more likely to choose familiar social partners when they are in a constrained-time scenario, but not more likely to choose a familiar social partner when in an unconstrained-time scenario. 
Fung, Carstensen, and Lutz (1999) set out to find whether there were differences in social preferences between young and old adults when time was viewed as unlimited or expanded. A median split was used to divide participants into two age groups: the younger group (45 years or younger) and the older group (older than 45 years). Participants read an unconstrained time scenario and chose the social partner with whom they would prefer to spend their free time. The time-unconstrained scenario and the social partner options were identical to those used in Carstensen and Lutz's (1990) study. After selecting a social partner, participants were presented with a second, time-extended scenario as follows:

Now imagine this situation: Last week you found out from your new doctor about a new medical advance that insures you will enjoy 20 more years beyond the age you expected to live, in reasonably good health. Today you have half an hour of free time with no pressing commitments. You decided to spend this time with another person. Assuming that the following three people are available to you, with which person would you choose to spend time?

The same social partner options were then offered. The results showed that when time was viewed as unlimited, the older group chose the familiar social partner significantly more often than did the younger group. When time was extended, the percentage of participants in the older group that chose the familiar social partner decreased significantly, but did not change for the younger group. This finding implies that social preferences and motivations change as the perception of time is extended, but only for older adults. In other words, older adults are more likely to make decisions like that of a younger adult when they have more time than they previously thought. This supports the proposition of SST that when people perceive they have greater amounts of time left, they are less likely 
to chose to spend time with a familiar social partner and more likely to choose to spend time with a new social partner.

In Study 2, Fung et al. (1999) sought to generalize SST cross-culturally. These researchers applied SST to Hong Kong Chinese residents in hopes of replicating previous SST results, and thus further validating the theory.

Participants were given the same time-unconstrained scenario as in Study 1 and the following time-constrained scenario:

Imagine that you will emigrate to another country in a few weeks - by yourself. No member of your family and your current social circle will be accompanying you on this trip. Although you are preparing for your big departure, you find that you have half and hour of free time, with no pressing commitment. You have decided that you'd like to spend this time with another person. Assuming that the following three people are available to you, which person would you choose to spend that time with?

Each participant chose from among the same social partners used in Study 1. The results showed that in time-unconstrained scenarios, older adults chose the familiar social partner more often than did younger adults. This difference was not significant, which may suggest that older Hong Kong Chinese residents are slightly more collectivistic than younger Hong Kong Chinese residents. In the time-constrained scenario, $89 \%$ of younger adults and $90 \%$ of older adults chose to spend their time with a familiar social partner. Despite differences between American (individualistic) and Asian (collectivistic) cultures, time constraint has a comparable effect on social preferences, strengthening the generalizability of SST.

In Study 3, Fung et al. (1999) looked at a sociopolitical ending as a time constraint in order to test SST. After over 150 years of being a British colony, Hong Kong returned to the People's Republic of China in 1997. Prior to this 
sociopolitical transition, individuals were flooded with propaganda anticipating the end of life as Hong Kong citizens knew it. Polls indicated that the majority of Hong Kong citizens believed their standard of living, personal freedoms, family prospects, as well as Hong Kong's prospects and political system would be threatened. Many people planned for the turnover or emigrated. It was clear that this transition would mark the end of an era. Fung et al. (1999) hypothesized that this sociopolitical transition would result in an increased preference for familiar social partners in younger and older Hong Kong citizens, given this naturally occurring constraint scenario.

Study 3 was conducted 2 months before the transition. Only timeunconstrained scenarios were presented to participants. Participants were simply asked to imagine that they had a half-hour of free time and to choose with whom they would like to spend their time. The results showed that both a majority of younger and older adults preferred a familiar social partner in a timeunconstrained scenario, with no significant difference between the two groups. Even when the scenario was time-unconstrained, the real-world sociopolitical ending in Hong Kong was powerful enough to influence social partner preferences typically found in experimental manipulations of time perspective. As a follow-up, Study 3 was replicated 1 year after the transition to see if social preferences changed yet again for younger adults. The results showed that younger adults in Hong Kong no longer had a significant preference for a familiar social partner in a time-unconstrained scenario, but the vast majority of older adults in Hong Kong still chose a familiar social partner in the timeunconstrained scenario. Post-transition, the younger adults no longer had an 
impending, real-world time constraint, therefore the percentage of participants that chose a familiar social partner in the time-unconstrained scenario dropped substantially. However, older adults still faced the time constraints of having dwindling years to live. Thus, they remained more likely to prefer a familiar social partner. The results of these studies indicate that the perception of time, whether experimentally manipulated or naturally imposed, is a powerful factor in determining social preferences.

In a 1998 study, Carstensen and Fredrickson looked at HIV status as an influence on social perceptions. The participants included three groups of homosexual men with similar chronological ages: an HIV-negative group, an HIV-positive group without symptoms of AIDS, and an HIV-positive group with symptoms of AIDS. All participants completed a questionnaire to measure perceptions of social support and a card-sort task to measure mental representations of potential social partners on the basis of similarity. The results showed that affective potential, or the anticipated positive or negative affect resulting from a social interaction, was most important for HIV-positive gay men with AIDS symptoms when choosing a potential social partner. Affective potential was not as important for HIV-positive gay men without AIDS symptoms or HIV-negative gay men. Information seeking, or how much an individual would seek information in order to become acquainted with a social partner, was found to be most important for HIV-positive gay men without AIDS symptoms, and least important for HIV-positive gay men with AIDS symptoms. Future contact, or the likelihood of seeing a social partner in the future, was least important for the HIV-positive gay men with AIDS symptoms and most important for HIV- 
negative gay men, with the HIV-positive gay men without AIDS symptoms falling in-between. In other words, the importance of affective potential increased with increased threat to death and the importance of future contact and information seeking declined with decreased threat of death. This research supports SST in that time, as constrained by impending death, heightens the salience of the emotional qualities of a relationship. In other words, as individuals confront death, they appear to prefer social partners based on how they feel in relation to them, rather than what they may learn from them.

Wright and Patterson (2006) looked at the role of friendship style and SST on perceptions of the quality of friendships over the lifespan. Friendship styles were categorized as discerning (relatively few close friends over the lifespan), independent (new friends made easily and often based on shared activities), and acquisitive (a core group of friends with openness to new friends based on activities). Participants were assigned to a young group, middle-aged group, or old group. They read brief descriptions of each friendship style and were asked to indicate which friendship style best fit them. The results showed that young and middle-aged participants were more likely to indicate an independent friendship style as compared to the older group. Middle-aged and older participants were more likely to indicate a discerning friendship style. These outcomes are congruent with SST in that as people age, they endorse being more selective in their friendships.

This study also looked at homophily (i.e., a tendency to associate and bond with similar social partners), emotional support, and quality of talk in relation to friendship style. While no differences were found between friendship style based 
on homophily, individuals with a discerning friendship style reported more emotional support and higher quality talk within their friendships. Because most individuals who indicated a discerning friendship style were middle-aged and older, this fits with SST in that more weight is put on emotional support and emotion regulation as people age. Furthermore, higher quality talk for middleaged and older persons may be related to their desire to invest more in current relationships. This is consistent with SST because middle-aged and older individuals may be more invested in preserving and enriching the relationships they already have.

SST postulates that as individuals age, emotions become more salient and people try to hold on to positive emotions. In 2006, Pruzan and Isaacowitz used eye-tracking technology to support this theoretical proposition. The participants in their study were first-year college students and graduating seniors, with graduation marking a social ending. Participants were shown 24 slides that each consisted of two photos of faces. Twelve of the slides paired an emotionally neutral face with a happy face, and the other 12 slides paired an emotionally neutral face with a sad face. The eye-tracking technology measured eye movement, which served as the dependent measure of visual attention. The results showed that seniors selectively avoided images of the sad faces, whereas first-year students did not. This supports the emotion-regulation component of SST in that college seniors who are approaching the social end of their college experience are more likely to regulate emotions by avoiding images depicting negative emotions. This study also utilized the Positive and Negative Affect Scale (PANAS) to measure differences in positive and negative affect between senior 
and freshman participants. Pruzan and Isaacowitz found that seniors exhibited significantly higher positive affect than sophomores. In regards to negative affect, seniors demonstrated a statistical trend of exhibiting less negative affect than sophomores.

In a follow up study, Xing and Isaacowitz (2006) sought to find out whether inducing an emotionally motivated state would yield positivity bias and negativity avoidance in attention. An emotionally motivated state was hypothesized to mirror the motivation of older adults, while an informationmotivated state would mirror the motivation of younger adults. Furthermore, they examined whether these manipulated emotional states would yield in a positivity bias with regard to memory. In the emotionally motivated condition, clients read the following instructions:

You are going to see 30 real-world images. Each will be presented in the center of the screen for $10 \mathrm{~s}$. You may look wherever you want. The most important thing is to try to manage how you feel as you see these images.

In the information-motivated condition, participants read the following instructions:

You are going to see 30 real-world images. Each will be presented in the center of the screen for $10 \mathrm{~s}$. You may look wherever you want. The most important thing is to get as much information as possible from each image.

Participants were shown negative, positive, and neutral images from the International Affective Picture Systems (IAPS) while left eye movement was tracked. The results of eye tracking showed that participants in the emotionally motivated condition viewed negative images significantly less than did participants in the information-motivated condition. Emotionally motivated 
participants also viewed negative images significantly less than positive images within emotionally motivated condition. These results support SST in that when people are emotionally motivated, like time-constrained adults, they prefer positive stimuli and avoid negative stimuli.

Fredrickson (1995) studied the socioemotional behavior of college students who either were facing or were not facing the time-constraint of graduation. Students were 19 graduating seniors, 19 juniors and sophomores, and 28 freshmen. Participants completed a Daily Activity Report every day for 3 weeks. On the report, participants indicated the amount of time spent with close friends compared to time spent with acquaintances (time selectivity), and indicated how emotionally intense each interaction was. The results showed no significant difference between class year and how much time was spent with acquaintances versus close friends. However, when examining the perceived emotional intensity of their interactions, differences did emerge. Graduating seniors reported their interactions with close friends to be significantly more emotionally intense than their interactions with acquaintances. Freshmen, sophomores, and juniors did not indicate a significant difference between the emotional intensity of interactions with their close friends as compared to acquaintances. In other words, seniors differentiate between the level of emotional intensity in interactions with close friends versus acquaintances, whereas freshman, sophomores, and juniors do not make this differentiation. This finding suggests that seniors have more significant emotional involvement with their close friends, indicating greater importance of their close friendships. 


\section{Terror Management Theory}

Terror Management Theory (TMT) postulates that when mortality becomes salient, people more intensely defend their culturally based worldviews (Arndt, Greenberg, Pyszczynski, \& Solomon, 1997), their political beliefs (Vail, Arndt, Motyl, \& Pyszczynski, 2012), and have more aversive reactions to those who are culturally dissimilar (Bassett \& Connelly, 2011) in order to buffer, or protect, themselves against the terror of death. Researchers of TMT have also examined the degree to which people seek out and value meaningful interpersonal relationships. For the purpose of the current study, the TMT literature will focus on the reciprocal relationship between mortality salience and interpersonal relationships. Research on TMT has shown that mortality salience can enhance the motivation to maintain and nurture interpersonal relationships (Vail, Juhl, Arndt, Vess, Routledge, \& Rutjens, 2012).

Hirschberger et al. (2002) examined the effects of mortality salience on mate selection. Israeli undergraduates completed a self-esteem scale and a scale that measured ideal mate-selection standards. The ideal mate-selection scale tapped into such factors as interpersonal skills, intellectual skills, physical attractiveness, interpersonal power, and social status. After completing the scales, participants answered two short questions that primed awareness of their mortality, a neutral topic, or an intense physical pain. Then, participants were assigned to one of two additional conditions. In the first of these conditions, participants were given the ideal-mate selection scale again and asked to rate the extent to which they would be willing to compromise and deviate from their standards for an ideal mate. They were instructed to imagine that they were 
considering a potential romantic partner for marriage. In the second condition, participants completed a scale that measured their preferences for television programs. The results showed that individuals with high self-esteem were less likely to compromise their ideal-mate selection standards. However, when mortality was primed and made salient, all individuals were significantly more likely to compromise their ideal-mate selection standards regardless of their level of self-esteem. These findings indicate that individuals are highly motivated to form a romantic relationship under mortality salient conditions, even if it means finding a less than ideal mate. It is important to note that because ideal-mate selection characteristics did not reflect cultural worldviews, participants were not sacrificing their worldviews to attain a partner. Rather, they were lowering their standards so they could establish a committed relationship. This reflects the component of TMT that proposes people are motivated to acquire meaningful relationships when mortality is salient.

In three similar studies Hirschberger et al. (2002) examined the relationship between mortality salience and relationship commitment. Undergraduates at Bar-Ilan University comprised the sample in these studies. Depending on the study, participants completed various surveys related to romantic commitment, judged social transgressions, or were reminded of relationship problems. These studies yielded several noteworthy findings. First, mortality salience was significantly associated with increased feelings of romantic commitment. That is, increased awareness of death led participants to report higher levels of relationship commitment as compared to participants in nonmortality salient conditions. Second, when mortality salience was primed, 
thinking about one's commitment to a partner decreased the severity with which participants rated social transgressions relative to participants who were not asked to think about commitment to their partner. This finding implies that romantic commitment may decrease the rate at which people cling to conservative values, a common occurrence in TMT, thus acting as a buffer against mortality salience. Lastly, participants who were instructed to think about their relationship problems had greater accessibility to death-related thoughts. This suggests that negative thoughts about relationships can elicit thoughts of mortality. Each of these findings stresses the important reciprocal effects that relationships and mortality salience have on each other.

Given the importance of interpersonal relationships, Cox and Arndt (2012) investigated the effect of mortality salience on perceived regard from romantic partners. Participants read a list of characteristics and indicated how their romantic partner would perceive them on each trait (i.e., perceived regard) after either a mortality-salience manipulation or a pain-salience manipulation. This study was replicated, but with participants indicating how an average person would regard them on each trait. The results showed that individuals exaggerated how positively their romantic partners would see them when mortality was made salient, but not when physical pain was salient. Participants did not exaggerate how an average person would see them, no matter the type of salience prime. These results suggest that romantic relationships act as a buffer, or reduce anxiety, related to morality salience because of the positive regard individuals believe they receive from their romantic partners. In a subsequent study, Cox and Arndt (2012) found that positive regard from a romantic partner decreased 
participants' likelihood of generating death-related thoughts on a word-stem completion task. In other words, positive regard from a romantic partner also acts as a buffer, or protects the individual, against the accessibility of mortalityrelated thoughts. These results are consistent with TMT in that intimate relationships appear to buffer the terror of death.

Schimel, Wohl, and Williams (2006) looked at the effects of mortality salience on forgiveness. Participants were primed either to think about their death or an unpleasant experience of going to the dentist. Then, participants read an article about either (a) a hometown hockey-team player committing a foul against a rival hockey-team player (ingroup member) in an anticipated game or (b) a rival hockey-team player (outgroup member) committing a foul against a hometown hockey-team player. They found that mortality salience increased forgiveness toward ingroup members who had committed a foul, but did not affect forgiveness towards outgroup members who had committed a foul. Forgiveness is often considered a standard toward which humans should strive, whether intrapersonally for the self or interpersonally for a transgressor. Not only does forgiveness serve as a value that people strive for and cherish, but increased forgiveness also benefits humans by preserving the relationships that we have. Thus, mortality salience can strengthen our current relationships as well as aid in emotion regulation. This is particularly true because we appear more likely to forgive ingroup members, or those with whom we have relationships, after reminders of our own mortality. Further, forgiveness of ingroup members may reflect a respected cultural value when mortality is salient. 
Ties that Bind SST and TMT

Having reviewed SST and TMT and selected empirical tests of these theories, I will identify the critical elements from these studies that are especially relevant to the purpose of the present research. Constrained-time perception is the first common critical element. Previous studies have identified that time perception affects choices and behavior in interpersonal relationships. Although SST research has examined the significance of life changes among college-age students, TMT studies have not dealt with real world endings and time constraints for this demographic group. Previous research on time constraints in college students also lacks a consistent method for priming students to think about graduation and the implications of this life transition. The second critical element is emotion regulation. SST postulates that individuals strive to regulate their emotions when facing a social ending. Previous research has confirmed unconscious attempts to regulate emotion through eye tracking technology (Pruzan \& Isaacowitz, 2006), but little is known about whether or not there is a conscious connection between emotion regulation and social transitions. Do undergraduates approaching graduation consciously make decisions because they know they will be fulfilled through the route they choose? The last critical element that is germane to the current study is how and why college undergraduates make meaningful choices as they approach transitions. Research has shown that undergraduates facing transitions are inclined have more intense relationships with social partners (Fredrickson, 1995), but research have not found that they necessarily spend more time with familiar social partners. Do undergraduates approaching graduation make certain decisions because they 
anticipate the end of close relationships, do they have more intense relationships because they choose to, or do other factors enter in to this decision-making process?

When reviewing the literature, it is important to note the criticisms of prior research. One criticism of Frederickson's 1995 research is that most of the participants were living in university dorm rooms. Due to the fact that participants primarily lived in the dorm rooms, they may have had less perceived choice about with whom to spend their time. Although this may affect how much time was spent with close friends compared to acquaintances that participant's indicated, this did not affect differences in emotional selectivity. Pruzan and Isaacowitz (2006), found that seniors in college avoided emotionally negative stimuli, but this study did not address the actual choices that the same students were making. They may have avoided negative stimuli, but this does not reveal what seniors do in their day-to-day lives to avoid negative emotions, if anything at all. The common method in SST research involves forced choice socialpartners post-manipulation. While these scenario-based methods are effective at finding differences in social-partner selection, they are dependent on a hypothetical scenario that may not accurately reflect what a participant would choose in real life. Further, the scenarios in SST research have not used graduation as a social ending in which participants may imagine themselves. The terror management literature is limited to studies of the effects of mortality salience on romantic relationships. This literature does not delve into the effects of mortality salience on friendship choices, a large limitation. Some parts of the 
current research reflect and attempt to correct what is lacking methodologically in these studies.

\section{Research Questions}

Based on the review of the previous literature, there are five main questions that are addressed by the current research. First, is there a difference between sophomores and seniors in the types of decisions that they make naturally? Second, is there a difference between sophomores and seniors in the types of decisions that they make when primed to think about graduation? Third, is there a difference in how deliberate sophomores and seniors are when making decisions? Fourth, is there a difference between sophomores and seniors in their experience of negative and positive affect when primed or not primed? Finally, is there a difference between sophomores and seniors in their experience of positive and negative affect after making decisions on how they intend to spend their time?

The previous research questions are important to answer so as to find how seniors and sophomores differ in intended decisions and affect, if at all. Previous research has not been clear or extensive in comparing the choices and affect of seniors and sophomores in university. These tests will be helpful in developing appropriate ways to motivate students in university course work and understanding what is important to students based on the time they have left until graduation. Based on previous literature and the basic components of SST and TMT, the following hypotheses were made about the results of the present study. In particular, hypotheses 1-10 are based on SST and TMT theories and previous literature (Carstensen \& Frederickson, 1998; Dudley \& Multhaup, 2005; 
Frederickson \& Carstensen, 1990; Fung et al. 1999) that states that individuals approaching a social ending will choose to spend time with familiar social partners more often than individuals who are not approaching a social ending. Hypothesis 11-14 are based on SST, which postulates that older adults spend greater time making decisions (Löckenhoff, 2011). Previous research lacks comparisons between undergraduate students, so these research questions are exploratory. Hypotheses 15-18 were exploratory because there is some discrepancy between previous research results and the implications of SST and TMT on affect.

\section{Hypotheses}

\section{Activity - Time Selectivity Matrix}

1. Seniors with or without a graduation-salience prime will report spending a greater proportion of time in social situations than in academic situations, across level of meaning.

2. Seniors with or without a graduation-salience prime will report spending a greater proportion of time in familiar and meaningful situations than in novel and future-focused situations, across situations.

3. Seniors with a graduation-salience prime will report spending a greater proportion of time in familiar and meaningful social situations than seniors without a graduation-salience prime.

4. Seniors with a graduation-salience prime will report spending a greater proportion of time in familiar and meaningful academic situations than seniors without a graduation-salience prime. 
5. Sophomores with a graduation-salience prime will report spending a greater proportion of time in social situations compared to sophomores without a graduation-salience prime.

6. Sophomores with a graduation-salience prime will report spending a greater proportion of time in meaningful academic situations than sophomores without a graduation-salience prime.

7. Seniors with a graduation- salience prime will report spending a greater proportion of time in familiar meaningful activities than sophomores with a graduation-salience prime, across situations.

8. Seniors with a graduation-salience prime will report spending a greater proportion of time in social situations than sophomores with a graduationsalience prime, across level of meaning.

9. Seniors without a graduation-salience prime will report spending a greater proportion of time in familiar and meaningful activities than sophomores without a graduation-salience prime, across situations.

10. Seniors without a graduation-salience prime will report spending a greater proportion of time in social situations than sophomores without a graduationsalience prime, across level of meaning.

\section{Deliberation}

11. Seniors without a graduation salience prime will report significantly higher deliberation scores than sophomores without a graduation salience prime. 12. Seniors with a graduation salience prime will show higher deliberation scores than sophomores with a graduation-salience prime. 
13. Seniors with a graduation-salience prime will deliberate more than seniors without a graduation salience prime

14. Sophomores with a graduation-salience prime will show more deliberation than sophomores without a graduation salience prime I-PANAS-SF

15. For all participants with a graduation-salience prime, positive affect will go down and negative affect will go up post-prime, compared to the baseline scores.

16. For all participants with a graduation-salience prime, positive affect will go up and negative affect will go down post-Time Selectivity Matrix, compared to the post-prime scores.

17. Seniors with a graduation salience prime will show a greater decrease in positive affect and a greater increase in negative affect from baseline to postprime compared to seniors without a graduation salience prime.

18. Seniors with a graduation salience prime will show a greater increase in positive affect and a greater decrease in negative affect from post-prime to postTime Selectivity Matrix compared to seniors without a graduation salience prime- 


\section{CHAPTER III}

\section{METHOD}

\section{Participants}

The participants in this study were undergraduate sophomore $(N=34)$ and graduating senior $(N=48)$ students at a large Midwestern university. There were 53 female participants, 28 male, and 1 participant that did not indicate their gender. The mean age of participants was $M=21.09(S D=1.549)$. Sophomores were chosen because they have had a reasonable amount of time to adjust to university life (e.g., no longer feeling homesick, having made friends). Further, sophomores are distinctly different from seniors in that they have more time left until graduation, and thus, are less likely to perceive that there is a constraint to their time at the university. Graduating seniors were chosen because they are more likely to perceive a distinct, limited amount of time left at the university. Senior participants must have indicated that they were expecting to graduate at the end of the semester in which they took the survey for their data to be included in the research. For participation in the survey, students were offered the opportunity to enter a drawing for a $\$ 50$ Amazon.com gift card.

\section{Materials}

\section{Activity - Time Selectivity Matrix}

To measure the way that sophomores and seniors intended to spend their time, participants completed a matrix grid indicating how many hours they 
intended to spend participating in four activities during the week following the survey (see Appendix A). Two of the activities were academic in nature and two were social in nature. Within these academic and social domains, one activity represented a familiar and meaningful decision and one option represented a novel and future-focused decision. The purpose of this matrix was to identify how university students intended to spend their time in four realistic activities. The items are not mutually exclusive (i.e., the participants do not need to choose between one activity or the other), because in real, day-to-day life the participants may be able to participate in each of the activities over the course of each day. Rather than collecting data that is unrealistic, the goal of this matrix was to gather information on the proportion of time spent in each of the activities. This method was chosen and developed by the author and her thesis committee because it is similar to the daily activity report used in previous research on SST with college students (Frederickson, 1995).

\section{Deliberation Item}

Participants completed a single item to measure how deliberate they were in making their Time - Selectivity Matrix decisions. Participants answered the question "How deliberate were you when making the previous decisions (i.e., how much thought or care did you put into your decisions before selecting an answer)" on a 5-point Likert-scale $(1=$ Very slightly or not at all, $2=A$ little, $3=$ Moderately, 4 = Quite a bit, 5 = Extremely). This item had not been previously used in research. 


\section{I-PANAS-SF}

Participants completed the internationally validated Positive Affect Negative Affect Schedule Short Form (I-PANAS-SF, see Appendix B), a version adapted by Thomas (2007) from the original PANAS (Watson, Clark, \& Tellegan, 1988). The I-PANAS-SF was used to measure participants' positive and negative emotions. Specifically, the I-PANAS-SF has 5 items that measure positive affect (PA) and 5 items that measure negative affect (NA) on a 5 -point Likert-scale $(1=$ Very slightly or not at all, $2=A$ little, $3=$ Moderately, $4=$ Quite $a$ bit, $5=$ Extremely). The 10 items in the I-PANAS-SF were chosen by purging each of the words from the original PANAS and assessing the reliability and the crossloadings. Thomas found the original PANAS and I-PANAS-SF correlated .92 $(p<$ .01) for PA items and $.95(p<.01)$ for NA items. The Cronbach alpha for PA items was .78 and 0.76 for NA items (Mackinnon, Jorm, Christensen, Korten, Jacomb, Rodgers, 1999). The test-retest reliability for the I-PANAS-SF was .84 $(p<.01)$ for both the PA and NA items. Convergent validity was tested by comparing the I-PANAS-SF to Diener's (1984) measure of subjective well-being (SWB) and Lyubomirsky and Lepper's (1999) subjective happiness scale. The PA items correlated positively with the SWB $(r=.33, p<.01)$ and subjective happiness scale $(r=.39, p<.01)$ and the NA items correlated negatively with the SWB $(r=-$ $.33, p<.01)$ and subjective happiness scale $(r=-.51, p<.01)$. The current study utilized a here-and-now instructional set: "Indicate to what extent you feel this way right now, that is, at the present moment.” The PANAS has been used in related research by Pruzan and Isaacowitz (2006) in which they found that 
seniors reported higher levels of PA than sophomores, but no difference in NA reported between by seniors and sophomores.

\section{Demographic Form}

Participants completed a demographic form (see Appendix C). The demographic form gathered information either directly or indirectly relevant to this study's research questions. Directly relevant information includes the participant's year in university. Indirectly relevant information includes the chronological age, gender, current living situation, and plans after graduation.

\section{Procedure}

Approval was obtained through the university's Institutional Review Board to conduct the research. Participants were recruited through the university email listserv. An invitation to participate and hyperlink to the study were sent to students who had previously opted-in to receive contact about participating in research. Participants were told that the purpose of the study was to examine the preferences of college students. If students chose to participate, they selected the hyperlink and were directed to an informed-consent document. If the student agreed to the informed consent, they were randomly assigned to a graduation salience condition or non-graduation salience condition survey. Random assignment was executed using randomizer html coding. Surveys were completed entirely online.

For their first survey task, participants completed the I-PANAS-SF to measure their baseline PA and NA. Then, participants in the graduation salience condition were asked to mark on a line with a sliding bar how much time they have left until graduation. In addition, those in the graduation-salience condition 
were asked to indicate, "How likely is it that you will experience all that you were hoping to experience in college prior to graduation?” They indicated this with a percentage from 0-100. These two procedural components served as the graduation-salience prime. Those in the non-graduation salience condition were asked to mark on a line how much time they have left until their next shopping trip. In addition, those in the non-graduation salience condition were asked to indicate, "How likely is it that you will buy all that you were hoping to purchase?" They indicated this with a percentage from 0-100 as well. The purpose of the non-graduation salience prompt was to provide a comparable, but neutral question to serve as the experimental control and to equivalent the time it took to complete the survey.

Immediately after the graduation salience prime or the non-graduation salience prompt, the participants completed the I-PANAS-SF to measure any selfreportable changes in PA or NA. Next, participants completed the Activity - Time Selectivity Matrix to indicate how they intended to spend their time in each of the four activities during the following week. After the Activity - Time Selectivity Matrix, participants responded to the Deliberation Item. Then, participants completed the I-PANAS-SF a final time, to measure any possible changes in PA or NA that may be related to how they indicated they would spend their time.

Finally, participants completed the demographic survey. Once they clicked the "Next" button after completing the demographic survey, participants were thanked for their participation in the research and were provided with a link to click on if they were interested in being entered into a drawing for an Amazon.com gift card. The link took the participant to a survey that was 
completely separate from the previous survey to ensure the participant's confidentiality.

There were two email deployments, occurring in different but consecutive semesters. In the first deployment the email was sent out to sophomore and senior university students, as identified by credit hours through the university registrar. There were significant discrepancies between participant's selfidentification and the university's identification of students' year in university (e.g., the student identified as a junior because it was their third year at the university but only had enough credit hours to be identified as a sophomore by the registrar), resulting in low numbers of eligible participants. The survey was deployed a second time and was sent to all university students who had previously chosen to opt-in to research. Data from participants who indicated that they were a sophomore or a graduating senior were included in the analyses.

\section{Design}

This study included two between-group conditions. The first was the participant's year in university (sophomore, senior). The second was salience condition (graduation salience, non-graduation salience). Crossing these independent variables yielded a 2 (year) $\times 2$ (salience) design, in which the dependent variables were proportion of time in four activities (Activity - Time Selectivity Matrix), deliberation (Deliberation Item), and positive and negative affect (I-PANAS-SF), which was repeated three times. 


\section{CHAPTER IV}

\section{RESULTS}

Eighty-two students completed all survey components of the study and were included in the analyses. Three participants skipped a single I-PANAS-SF item out of all three administrations. These missing data points were dealt with by calculating the mean PA or NA score for the administration in question (i.e., baseline, post-Graduation Salience, or post-Activity - Time Selectivity Matrix), and replacing the missing score with the calculated mean. One participant skipped the Activity - Time Selectivity Matrix entirely and was removed from the data analyses. The Outlier Labeling Rule was used to identify outliers in the data. One weak upper outlier score was found for NA in the third administration of the I-PANAS-SF; this datum was not removed from the dataset. There were 53 female participants, 28 male participants, and 1 participant who did not indicate gender. Forty-seven participants reported living in university housing, 4 in a sorority or fraternity house, 47 in an off-campus apartment or house, 3 with their parents in the area, and 1 selected other and explained that they lived at their offcampus internship site. Since there were only 4 participants who indicated living in a socially isolated environment (with their parents and at an internship site), the sample represents university students that are most likely to be socially engaged. 
A $2 \times 2$ (Year $\times$ Salience Condition $)$ Chi-square test was performed and no significant differences were found between the number of participants in each condition (Senior - Graduation Salience $=24$; Senior - Non-graduation Salience $=$ 25; Sophomore - Graduation Salience $=20$; Sophomore - Non-graduation Salience $=13), \mathbf{c}^{2}(1, N=82)=1.07, p=.30$. A $2 \times 2($ Year $\times$ Salience Condition $)$ ANOVA was run on the 5-point Likert scale question, "How much are you looking forward to graduation?" No significant main effects or interaction effects were found.

Of the 18 hypotheses in the study, only one significant finding was found related to Hypothesis 1, but in the opposite direction than predicted. A pairedsamples $t$-test was run to detect differences in the proportion of time in the four activities reported by seniors (i.e., academic, social, meaningful, and futurefocused). In regards to Hypothesis 1, there was a significant result in the opposite direction hypothesized, such that seniors reported intention to spend more time in academic activities during the following week than in social activities, $t(48)=$ 7.26, $p<.005 ; d=1.03$. In regards to Hypothesis 2 , seniors did not report a significant difference in the proportion of time they would spend in futurefocused or meaningful activities, $t(48)=1.34, p=.19$. Means and standard deviations for these results can be found in Table 1.

Six $2 \times 2$ (Year $\times$ Salience Condition) analyses of variance (ANOVAs) were run on the dependent variables (proportion of time in meaningful activities, social activities, meaningful social activities, meaningful academic activities, future social activities, and future academic activities) using year in university 
and graduation salience condition as independent variables. No significant main effects or interaction effects were produced by these ANOVA tests.

For Hypotheses 3 and 4, seniors in the graduation salience condition did not report significant differences from seniors in the non-graduation salience condition in the proportion of time in meaningful social activities, $F(1,78)=$ $0.186, p=.67$, or meaningful academic activities, $F(1,78)=0.153, p=.70$. For Hypotheses 5 and 6, sophomores in the graduation salience condition did not report significant differences compared to sophomores in the non-graduation salience condition in the proportion of time in social activities, $F(1,78)=0.002$, $p=.79$, or meaningful academic activities, $F(1,78)=0.00, p=.99$. For Hypotheses 7 and 8, seniors in the graduation salience condition did not report significant differences from sophomores in the graduation salience condition in the proportion of time in meaningful activities, $F(1,78)=0.00, p=.99$, or social activities, $F(1,78)=0.002, p=.79$. For Hypotheses 9 and 10, seniors without graduation salience prime did not report significant differences from sophomores without a graduation salience prime in the proportion of time in meaningful activities, $F(1,78)=0.00, p=.99$, or social activities, $F(1,78)=0.002, p=.79$. Table 2 presents means and standard deviations for the proportion of time spent in these activities by year in university and salience condition.

A $2 \times 2$ ANOVA was run to identify differences in deliberation scores between participants based on year in university and graduation salience condition. No significant main effects were found by year in university, $F(1,78)=$ $.488, p=.49$, or salience condition, $F(1,78)=.09, p=.76$, or interaction effects by year in university and salience condition, $F(1,87)=.30, p=.58$. Specifically, 
for Hypothesis 11, seniors in the non-graduation salience condition did not report significantly different deliberation scores than sophomores in the non-graduation salience condition. For Hypothesis 12, seniors in the graduation salience condition did not report significantly different deliberation scores than sophomores in the graduation salience condition. For Hypothesis 13, seniors in the graduation salience condition did not report significantly different deliberation scores than seniors in the non-graduation salience condition. Finally, for Hypothesis 14, sophomores in the graduation salience condition did not report significantly different deliberation scores than sophomores in the nongraduation salience condition. The means and standard deviations, found in Table 3, indicate that participants were on average "moderately" to "quite a bit" deliberate.

Reliability tests were run to check for internal consistency of the I-PANASSF. The three administrations of the PA scales yielded high levels of internal consistently as indicated by Cronbach alphas, $\alpha=.834, \alpha=.868$, and $\alpha=.901$, respectively. The three administrations of the NA scales yielded moderate to high levels of internal consistency, as indicated by Cronbach alphas, $\alpha=.764, \alpha=$ .803 , and $\alpha=.799$, respectively.

A $2 \times 2 \times 3($ Year $\times$ Salience Condition I-PANAS-SF administration $)$ repeated measures ANOVA was conducted to analyze reported changes in PA and NA scores over time. Mauchly's test of sphericity indicated that there was a violation in the assumption of homogeneity of variances for PA scale scores across administrations of the I-PANAS-SF, $\mathbf{c}^{2}(2)=16.60, p<.005$. For this reason, PA results were analyzed using a Huyhn-Feldt correction by 
recommendation of Girden (1992). With this correction, the results did not reveal a significant interaction between I-PANAS-SF administration (i.e., time) and year on PA scores as was predicted by Hypotheses $15,16,17$, and $18, F(1.774,156)=$ $.079, p=.91$. A main effect for time was found on PA, $F(1.77,156)=4.84, p=$ $.012, \eta^{2}=0.058$, although this finding was not related to any of these hypotheses. Specifically, the significant change by time was that PA scores overall went down from Time 1 to Time 2, but leveled off from Time 2 to Time 3. Mauchly's test of sphericity indicated no violation in sphericity for NA scores, $\mathbf{c}^{2}(2)=1.74, p=.42$, therefore three-way repeated measures ANOVA on NA scores was conducted without corrections. These results indicated no significant interactions between IPANAS-SF administration (i.e., time) and year on NA scores, as was predicted by Hypotheses $15,16,17$, and $18, F(2,156)=2.336, p<.10$ There was a main effect for time on NA scores, $F(2,156)=10.00, p<.005, \eta^{2}=0.114$. Specifically, the significant change by time was that NA scores overall went down overall from Time 1 to Time 3, gradually. This was unrelated to any of the above hypotheses. 
Table 1

Means and Standard Deviations of Seniors' Reported

Proportion of Time Selectivity by Activity

\begin{tabular}{l|c|c}
\hline \multicolumn{1}{c|}{ Activity } & $M$ & $S D$ \\
\hline Social & .65 & .15 \\
\hline Academic & .35 & .15 \\
\hline Meaningful & .54 & .21 \\
\hline Future & .46 & .21 \\
\hline
\end{tabular}

Note. Proportion of time spent in activities was calculated ipsatively. That is, the total proportion of time was added for each participant and divided by the total number of weekly hours the participant reported. 
Table 2

Means and Standards Deviations of Proportion of Time Spent in Activities by Year in University and Salience Condition

\begin{tabular}{|c|c|c|c|c|c|}
\hline \multirow[b]{2}{*}{ Salience } & \multirow[b]{2}{*}{ Year } & \multicolumn{2}{|c|}{ Social } & \multicolumn{2}{|c|}{ Meaningful } \\
\hline & & $M$ & $S D$ & $M$ & $S D$ \\
\hline \multirow[t]{2}{*}{ Graduation } & Sophomore & 0.332 & 0.14 & 0.459 & 0.14 \\
\hline & Senior & 0.323 & 0.15 & 0.446 & 0.19 \\
\hline \multirow[t]{3}{*}{$\begin{array}{l}\text { Non- } \\
\text { Graduation }\end{array}$} & Sophomore & 0.399 & 0.13 & 0.488 & 0.12 \\
\hline & Senior & 0.372 & 0.14 & 0.474 & 0.23 \\
\hline & & \multicolumn{2}{|c|}{$\begin{array}{l}\text { Meaningful } \\
\text { \& Social }\end{array}$} & \multicolumn{2}{|c|}{$\begin{array}{l}\text { Meaningful \& } \\
\text { Academic }\end{array}$} \\
\hline Salience & Year & $M$ & $S D$ & $M$ & $S D$ \\
\hline \multirow{2}{*}{ Graduation } & Sophomore & 0.178 & 0.11 & 0.282 & 0.13 \\
\hline & Senior & 0.17 & 0.11 & 0.276 & 0.15 \\
\hline \multirow[t]{3}{*}{$\begin{array}{l}\text { Non- } \\
\text { Graduation }\end{array}$} & S & 0.215 & 0.11 & 0.73 & 0.06 \\
\hline & Senior & 0.231 & 0.14 & 0.243 & 0.11 \\
\hline & & \multicolumn{2}{|c|}{$\begin{array}{c}\text { Future \& } \\
\text { Social }\end{array}$} & \multicolumn{2}{|c|}{$\begin{array}{l}\text { Future \& } \\
\text { Academic }\end{array}$} \\
\hline Salience & Year & $M$ & $S D$ & $M$ & $S D$ \\
\hline \multirow[t]{2}{*}{ Graduation } & Sophomore & 0.155 & 0.08 & 0.386 & 0.15 \\
\hline & Senior & 0.154 & 0.1 & 0.4 & 0.18 \\
\hline \multirow[t]{2}{*}{$\begin{array}{l}\text { Non- } \\
\text { Graduation }\end{array}$} & Sophomore & 0.184 & 0.7 & 0.328 & 0.13 \\
\hline & Senior & 0.142 & 0.1 & 0.384 & 0.21 \\
\hline
\end{tabular}

Note. Proportion of time spent in activities was calculated ipsatively. That is, the total proportion of time was added for each participant and divided by the total number of weekly hours the participant reported. 
Table 3

Deliberation Scores by Year in University and Salience Condition

\begin{tabular}{lcccc}
\hline \multirow{4}{*}{} & \multicolumn{2}{c}{ Graduation Salience } & \multicolumn{2}{c}{ Non-Graduation Salience } \\
\cline { 2 - 5 } & $\mathrm{M}$ & $\mathrm{SD}$ & $\mathrm{M}$ & $\mathrm{SD}$ \\
\cline { 2 - 5 } Sophomore & 3.35 & 0.75 & 3.31 & 0.63 \\
Senior & 3.37 & 0.77 & 3.52 & 0.77
\end{tabular}

Note. Deliberation scores were indicated on a 5-point Likert scale; 1 = Slightly, or not at all; 2 = A little; $3=$ Moderately; 4 = Quite $a$ bit; $5=$ Extremely. 


\section{CHAPTER V \\ DISCUSSION}

This research sought to find how nearness to graduation or thinking about graduation impacts students in regards to their affect, decisions about how best to utilize their time, and the thoughtfulness of those decisions. The study was based on SST and TMT, and aimed to add to the limited research that applies these theories to the lived situations that young adults experience. Overall, only 1 of 18 hypotheses was significant, but in the opposite direction than predicted. This significant result was likely a Type I error. The results are discussed in regards to their limitations and implications for future research.

The results of this study yielded significant results that contradicted Hypothesis 1. Despite research that individuals approaching a social ending are more likely to prefer spending time with familiar (i.e., meaningful) social partners (Carstensen \& Frederickson, 1998; Dudley \& Multhaup, 2005; Frederickson \& Carstensen, 1990; Fung et al., 1999), this did not appear to be true for this study's sample. Seniors reported an intention to spend a significantly greater proportion of time in academic activities than in social activities. Also, seniors did not produce significant differences between the proportion of time in meaningful activities versus future-focused activities. One explanation for this may be that seniors at the university do not view graduation as significant of a 
social ending as they may have in the past. This may be due to increased opportunities for social connections due to the availability of many social media outlets. In the past university seniors may have seen their graduation as a time to say goodbye to friends and move on to the next part of their lives. Nowadays, social media use is so prevalent that after graduation one can instantly message friends, video chat, share photos, and keep tabs on each other's lives with the click of a button. Graduation and physical separation from friends may not be as prominent of a concern anymore for college graduates. The participants in the current study were not only technologically connected enough to complete the survey, but they also demonstrated a presumably high level of technological engagement in that they agreed to participate (i.e., they were self-selected subset of the technologically connected undergraduate population that was sampled). Another reason that seniors may have reported spending more time in academic activities is because they chronologically fit with the general population of young adults that would typically report being more motivated by futurefocused activities, as has been shown in previous research (Carstensen, 1995; Frederickson \& Carstensen, 1990; Fung et al., 1999). In fact, $84.15 \%$ of participants (69 out of 82) reported having some type of future-focused goal for post-graduation, either in the form of finding a job or continuing their education to prepare for a career. So, while the results did not indicate that seniors were similar to older adults in their motivations, this research does suggest that seniors may be like the future-focused young adult population that has been previously researched in SST literature (Carstensen, 1995; Frederickson \& Carstensen, 1990; Fung et al., 1999). 
The results indicated that there were no significant differences between participants in their deliberation scores by year in the university or graduation salience condition. Participants on average indicated that they were moderately to quite deliberate when making their decisions. Previous research found that older adults (those nearer to a social ending) spent more time making decisions (Löckenhoff, 2011), but this element of SST theory was not evident in findings for the current study. One explanation for this may be that sophomores and seniors closeness in chronological age $\left(M_{\text {Sophomores }}=20.00, S D_{\text {Sophomores }}=1.66\right.$ vs. $M_{\text {Seniors }}$ $\left.=21.82, S D_{\text {Seniors }}=0.95\right)$ may have more of an effect on time spent making decisions than the impending social transition. The nearness in chronological age would imply that sophomores and seniors are not as receptive to this existential issue because they are both relatively young and do not live like they are dying, but rather like they will live long and prosper.

Hypotheses 15 and 16 were exploratory due to theoretical and empirical discrepancies between SST and TMT concerning emotional responses to stimuli that prime the salience of social endings (Frederickson, 1995; Pruzan \& Isaacowitz, 2006; Xing \& Isaacowitz, 2006). Although Pruzan and Isaacowitz (2006) found significant differences between seniors and sophomore on reported affect using the PANAS, the current study did not find any significant differences between participants' PA scores or NA scores by year or salience condition. The findings that PA and NA changed over time indicate that participants showed a slight drop in positive affect and more substantial decline in negative affect across administrations of the I-PANAS-SF, but not changes that were predicted 
by the this study. It would appear that participants became more comfortable as they completed the online survey.

\section{Limitations}

First, the sample size of this study was limited due to initial difficulties in recruiting participants with the targeted demographics (i.e., sophomores and graduating seniors). The second email-deployment of the survey attempted to correct these problems, without much success. Thus, a reduction in statistical power may have contributed to the lack of significant findings for virtually all of the hypotheses. A second limitation is that the population was self-selected and limited to one Midwestern university, and was therefore not representative of the population of university undergraduates. Third, the sample had more females than males, adding to the non-representativeness of the sample.

Another limitation has to do with the graduation salience and nongraduation salience manipulations. Because there were no significant results for the graduation and non-graduation salience conditions, it is reasonable to conclude that the graduation salience manipulation was not powerful enough to elicit an emotional or motivation-changing reaction. Participants in the graduation salience condition were asked to mark on a line with a sliding bar how much time they have left until graduation. In addition, they were asked to indicate, "How likely is it that you will experience all that you were hoping to experience in college prior to graduation?" Participants in the non-graduation salience condition were asked to mark on a line how much time they have left until their next shopping trip. In addition, they were asked to indicate, "How likely is it that you will buy all that you were hoping to purchase?” The graduation 
and non-graduation salience manipulations were created by the researcher and her thesis committee for this study in an attempt create a comparable salience condition to those that have been used in previous research (Dudley \& Multhaup, 2005; Frederickson \& Carstensen, 1990; Fung at al., 1990), but one that applied more directly to the lived situation of university students. The researchers embarked on a new pathway with this manipulation due to the fact that only a few studies pertain to the current one with college students and none use graduation in a manipulation or prime (Dudley \& Multhaup, 2005; Frederickson \& Carstensen, 1990; Fung at al., 1990). Another limitation is the brief single item used to measure deliberation. This item was also created by the researcher and her thesis committee, and may not have fully captured the differences in deliberation that participants experienced when filling out the Activity-Time Selectivity Matrix.

\section{Implications and Future Directions}

The initial goal of this study was to contribute to research on SST and TMT that could be directly related to "senioritis" and to find ways to motivate senior students. "Senioritis" can be a particularly frustrating experience for both seniors who begin to lose focus in school as well as teachers who strive to keep students engaged in their studies. This researcher had hoped to find that seniors were making more meaningful and more social decisions in response to their impending graduation. If this were to have been the case, that seniors were in fact spending more time in meaningful and social activities, this finding would have been a starting point for developing interventions in educational settings to motivate seniors. However, this was not demonstrated in the study, and it 
remains unclear why senior students may not perform as well in their senior year. This research did not find that seniors were making meaningful decisions because of an impending the social transition, but this idea should continue to be examined in future research.

Future research should be directed toward discovering more specific reasons and motivations behind changes in academic engagement of seniors per the common understanding of "senioritis". One way to do this would be to have more reliable measures of time selectivity, such as using a weekly diary. A weekly diary can measure actual (vs. anticipated) preferences for various activities (e.g., academic, social) over a longer period of time if participants are consistent and follow through with logging their activities.

Another possible route for future research would be to develop a reliable and valid measure of deliberation. The development of a psychometrically sound measure of deliberation, particularly one that would apply to university students, would be beneficial in detecting differences in how much time and effort students spend in responding to the Time Selectivity Survey or some other tool to access how their preferred use of time. Future research with psychometrically strong measures may find that seniors do spend more time considering how that they will spend their time, because time is more fleeting for them.

Another potential area for future research would be investigations of the effects of social media on the anticipation of graduation. Previous studies using university students were conducted prior to the advent of Facebook, which was not released to the public until 2005 (Boyd \& Ellison, 2007) and before social media use was as prominent as it is today. Therefore, previous research did not 
have a reason to account for social media usage among participants. In the current day and age, college graduates have fast and easy access to their peers through Facebook, Twitter, e-mail, FaceTime, etc. Although graduation may have meant a more permanent separation from college friends in the past, college seniors now may not worry about the significance of these social endings as much as they may did before. Future research should investigate university students' social media usage, engagement, and enjoyment of social media use. Furthermore, investigating seniors understanding of their impending social transition in terms of how they will stay in contact with their friends would be worth investigating within the theoretical framework of SST. With the use of social media, social transitions are blurring, and SST will need to start address the effects of social media on social transitions if the theory is to remain current.

Of the studies that were reviewed that used explicit social-ending scenarios to prime participants, none used graduation as a social ending (Dudley \& Multhaup, 2005; Frederickson \& Carstensen, 1995; Fung et al., 1999). In terms of the graduation and non-graduation manipulations, future researchers could conduct mixed-method studies to learn about the lived experiences of current university students as they approach graduation. By using mixed methods, researchers could establish a rich qualitative understanding of seniors' experiences that would complement quantitative efforts to understand changes in their affect and decisions. Researchers should also pilot test graduation salience manipulations in the future before administering them in a formal study. This would ensure that the manipulation would be sufficiently powerful to have a priming effect. If researchers are able to develop a method that would more 
effectively prime graduation salience, hypotheses derived from SST and TMT that pertain to the social transitions of graduating seniors could be tested.

Research on SST and TMT that applies directly to university students is extremely limited. The majority of this research has been conducted with eyetracking technology or diaries that are recorded over multiple weeks (Frederickson, 1995; Pruzan \& Isaacowitz, 2006; Xing \& Isaacowitz, 2006). One way to improve the methodological strength of research on the topic of how university students think, feel, and act in view of their impending graduation would be to develop efficient ways of gathering actual, day-to-day records of students' responses. One suggestion would be for future researchers to utilize the technology at their disposal, such as smart phones that are capable of downloading applications. With proper resources, future researchers may be able to design "diary" applications for research purposes that are strictly confidential. This would give participants an opportunity to provide fast, accurate, and convenient data to researchers.

Overall, the SST and TMT literature has room to grow, particularly in regards to how the propositions of these theories (e.g., responses to significant life transitions) apply to university students. Many SST and TMT studies have used hypothetical scenarios in their research (Carstensen \& Frederickson, 1998; Dudley \& Multhaup, 2005; Frederickson \& Carstensen, 1995; Fung et al., 1999; Hirchberger et al., 2002; Schimel et al., 2006), but few (e.g., Frederickson 1995) methods exist with which to understand how students actually feel, think, and act given impending significant life transitions (e.g., diary, eye-tracking). 


\section{REFERENCES}

Arndt, J., Greenberg, J., Pyszczynski, T., \& Solomon, S. (1997). Subliminal exposure to death-related stimuli increases defense of the cultural worldview. Psychological Science, 8, 379-385.

Bassett, J. F., \& Connelly, J. N. (2011). Terror management and reactions to undocumented immigrants: Mortality salience increase aversion to culturally dissimilar others. Journal of Social Psychology, 151, 117-120.

Boyd, D. M., \& Ellison, N. B. (2007). Social network sites: Definition, history, and scholarship. Journal of Computer-Mediated Communication, 13, 210230 .

Carstensen, L. (1995). Evidence for a life-span theory of socioemotional selectivity theory. Current Directions in Psychological Science, 4, 151-156.

Carstensen, L. (2006). The influence of a sense of time on human development. Science, 312, 1913-1915.

Carstensen, L. L., \& Fredrickson, B. L. (1998). Influence of HIV status and age on cognitive representations of others. Health Psychology, 17, 494-503.

Cox, C. R., \& Arndt, J. (2012). How sweet it is to be loved by you: The role of perceived regard in the terror management of close relationships. Journal of Personality and Social Psychology, 102, 616-632.

Deiner, E. (1984). Subjective well-being. Psychological Bulletin, 95, 542-575. Dudley, N. M., \& Multhaup, K. S. (2005). When familiar social partners are selected in open-ended situation: Further tests of the socioemotional selectivity theory. Experimental Aging Research, 31, 331-344.

Dunn, K. (2001). Students: The fourth-year itch. Teacher Magazine, 12(7), 1214.

Florian, V., Mikulincer, M., \& Hirschberger, G. (2002). The anxiety-buffering function of close relationships: Evidence that relationship commitment acts as a terror management mechanism. Journal of Personality and Social Psychology, 82, 527-542.

Fredrickson, B. L. (1995). Socioemotional behavior at the end of college life. Journal of Social and Personal Relationships, 12, 261-276. 
Fredrickson, B. L., \& Carstensen, L. L. (1990). Choosing social partners: How old age and anticipated endings make people more selective. Psychological Aging, 5, 335-347.

Fung, H. H., Carstensen, L. L., \& Lutz, A. M. (1999). Influence of time on social preferences: Implications for life-span development. Psychology and Aging, 14, 595-604.

Girden, E. D. (1992). ANOVA. Thousand Oaks, CA: Sage.

Greenberg, J., Solomon, S., Veeder, M., Pyszczynski, T., Rosenblatt, A., \& Kirkland, S. (1990). Evidence for terror management theory II: The effects of mortality salience on reactions to those who threaten or bolster the cultural worldview. Journal of Personality and Social Psychology, 58, $308-318$.

Hirschberger, G., Florian, V., \& Mikulincer, M. (2002). The anxiety buffering function of close relationships: Mortality salience effects on the readiness to compromise mate selection standards. European Journal of Social Psychology, 32, 609-625.

Hoover, E. (2003). Fighting "senioritis". Chronicle of Higher Education, 49(42). Retrieved from http://chronicle.com.libproxy.lib.ilstu.edu/article/FightingSenioritis/11191/

Kercher, K. (1992). Assessing subjective well-being in the old-old: The PANAS as a measure of orthogonal dimensions of positive and negative affect. Research on Aging, 14, 131-168.

Kwiatkowska, M., Knysz, B., Gąsiorowski, J., Łuszczńskan, A., \& Gladysz, A. (2011). The role of mechanisms of buffering anxiety in HIV carriers: A study within the terror management theory paradigm. Advances in Hygiene and Experimental Medicine, 65, 133-142.

Löckehoff, C. E. (2011). Age, time, and decision making: From processing speed to global time horizons. Annals of the New York Academy of Sciences, $1235,44-56$.

Lyubomirsky, S. \& Lepper, H. S. (1999). A measure of subjective happiness: Preliminary reliability and construct validation. Social Indicators Research, 46, 137-155.

Mackinnon, A., Jorm, A. F., Christensen, H., Korten, A. E., Jacomb, P. A., Rodgers, B. (1999). A short form of the Positive and Negative Affect Schedule: Evaluation of factorial validity and invariance across 
demographic variable in a community sample. Personality and Individual Differences, 27, 405-416.

mcgraw, t. (2004). Live Like You Were Dying. On Live Like You Were Dying [CD]. Nashville, TN: Curb Records.

Pruzan, K., \& Isaacowitz, D. M. (2006). An attentional application of socioemotional selectivity theory in college students. Social Development, $15,326-338$.

Schimel, J., Wohl, M. J. A., \& Williams, T. (2006). Terror management and trait empathy: Evidence that mortality salience promotes reactions of forgiveness among people with high (vs. low) trait empathy. Motivation and Emotion, 30, 214-224.

Thomas, E. R. (2007). Development and validation of an internationally reliable short-form of the Positive and Negative Affect Schedule (PANAS). Journal of Cross-Cultural Psychology, 31, 227-242.

Vail, K. E., III, Arndt, J., Motyl, M., \& Pyszczynski, T. (2012). The aftermath of destruction: Images of destroyed buildings increase support for war, dogmatism, and death thought accessibility. Journal of Experimental Social Psychology, 48, 1069-1081.

Vail, K. E., III, Juhl, J., Arndt, J., Vess, M., Routledge, C., \& Rutjens, B. T. (2012). When death is good for life: Considering the positive trajectories of terror management. Personality and Social Psychology Review, 16, 303-329.

Watson, D., Clark, L. A., \& Tellegan, A. (1988). Development and validation of brief measures of positive and negative affect: The PANAS Scales. Journal of Personality and Social Psychology, 54, 1063-1070.

Wright, K. B., \& Patterson, B. R. (2006). Socioemotional selectivity theory and the macrodynamics of friendship: The role of friendship style and communication in friendship across the lifespan. Communication Research Reports, 23, 163-170.

Xing, C., \& Isaacowitz, D. M. (2006). Aiming at happiness: How motivation affects attention to and memory for emotional images. Motivation and Emotion, 30, 243-250.

Yalom, I. D. (1980). Existential psychotherapy. New York: Basic Books. 
APPENDIX A

ACTIVITY - TIME SELECTIVITY MATRIX 
Please indicate how many hours you intend to spend on each of the following activities NEXT WEEK.

NOTE: The totals do not have to add up to 24 hours for each day.

\begin{tabular}{|l|c|c|c|c|c|c|c|}
\hline & Sun & Mon & Tues & Wed & Thurs & Fri & Sat \\
\hline $\begin{array}{l}\text { Spending } \\
\text { time with new } \\
\text { acquaintances } \\
\text { (people that } \\
\text { you don't } \\
\text { know that } \\
\text { well, but may } \\
\text { be good } \\
\text { friends with } \\
\text { in the future) }\end{array}$ & $(1-24)$ & $(1-24)$ & $(1-24)$ & $(1-24)$ & $(1-24)$ & $(1-24)$ & $(1-24)$ \\
\hline $\begin{array}{l}\text { Spending } \\
\text { time with } \\
\text { people who } \\
\text { are already } \\
\text { your close } \\
\text { friends }\end{array}$ & $(1-24)$ & $(1-24)$ & $(1-24)$ & $(1-24)$ & $(1-24)$ & $(1-24)$ & $(1-24)$ \\
\hline $\begin{array}{l}\text { Studying } \\
\text { solely for the } \\
\text { purpose of } \\
\text { getting a } \\
\text { better grade } \\
\text { in a class }\end{array}$ & $(1-24)$ & $(1-24)$ & $(1-24)$ & $(1-24)$ & $(1-24)$ & $(1-24)$ & $(1-24)$ \\
\hline $\begin{array}{l}\text { Reading or } \\
\text { doing other } \\
\text { academic } \\
\text { work because } \\
\text { you enjoy the } \\
\text { topic }\end{array}$ & $(1-24)$ & $(1-24)$ & $(1-24)$ & $(1-24)$ & $(1-24)$ & $(1-24)$ & $(1-24)$ \\
\hline
\end{tabular}


APPENDIX B

I-PANAS-SF 
This scale consists of a number of words that describe different feelings and emotions. Read each item and then mark the appropriate answer in the space next to the words. Indicate to what extent you feel this way right now, that is, at the present moment. Use the following scale to record your answers.

1

Very slightly, or not at all

$\begin{array}{ll} & \text { Upset } \\ & \text { Hostile } \\ & \text { Alert } \\ & \text { Ashamed } \\ \text { Inspired }\end{array}$

2

A little

3

Moderately
4

Quite a bit

5

\section{Extremely}


APPENDIX C

DEMOGRAPHIC QUESTIONNAIRE 
Please answer the following questions to the best of your knowledge.

Age

Gender

Year in university

Current living situation (please indicate one)

University housing (dorm room, Cardinal courts)

Sorority/Fraternity housing

Off-campus apartment/house

Living with parents

Other (please describe):

What are your plans after graduation?

How much are you looking forward to graduation?

1

Very slightly, or not at all
2

A little

3

Moderately

4

5

Quite a bit Extremely 
APPENDIX D

INFORMED CONSENT 
Please read this page carefully. You must be at least 18 years of age to participate in research.

The purpose of this research study is to examine the preferences of college students. It involves completing an Internet survey that should take no more than 30 minutes.

You will be asked to share some information about yourself. Your participation is voluntary. Refusal to participate involves no penalty. The risks associated with this study are no greater than everyday life. You may skip any question you do not wish to answer. You also have the right to withdraw at any time without penalty.

There are minimal risks to participating in this research, and all data will be kept confidential by the researchers. Benefits to participation include learning more about your academic and social priorities as a result of completing the survey. Moreover, after completing the survey, you will have the option of entering a raffle to win a $\$ 50$ gift card to Amazon.com. To enter the raffle, at the end of the survey you will be presented with a link to another survey so that you can provide contact information. If you choose to withdraw from the survey at any time, you can enter the raffle by selecting the exit button, and will be directed to the survey to provide contact information. All contact information will be kept confidential. This gift card may be viewed as taxable income by the IRS.

If you have questions about this research project, you may contact Dr. Michael Stevens, Department of Psychology, Illinois State University at (309) 438-8651 or mjsteven@ilstu.edu or Danielle Freund at dnfreun@ilstu.edu. Any questions regarding your rights as a research participant or research-related concerns may be directed to Research Ethics and Compliance, (309) 438-2529, rec@ilstu.edu. By clicking Next, I agree to participate in this research study. 